\title{
Action Potential Changes Due to Y1795H Mutation in Brugada Syndrome Patients: A Simulation Study
}

\author{
$*$ S Severi, $*$ S Vecchietti, ${ }^{\circ}$ I Rivolta, ${ }^{\circ} \mathrm{C}$ Napolitano, ${ }^{\circ}$ SG Priori, $*$ S Cavalcanti \\ *Biomedical Engineering Laboratory, DEIS, University of Bologna, Bologna, Italy \\ ${ }^{\circ}$ Molecular Cardiology Laboratory, Fondazione Salvatore Maugeri, IRCCS, Pavia, Italy
}

\begin{abstract}
Several mutations of the gene encoding for the cardiac sodium channel (SCN5A) are associated with Congenital Brugada syndrome $(\mathrm{BrS})$, but the assessment of their functional consequences with the experimental models is biased by technical limitations. To overcome such limitations we used a novel approach combining in vitro data and computer modeling. The Y1795H mutation of SCN5A was evaluated. A Markovian model capable to reproduce the kinetics of both wild type (WT) and mutant channels was incorporated into the Luo-Rudy comprehensive model of ventricular cells. Here presented results highlight the high sensitivity of simulated AP of virtual transgenic cells to the maximum conductance assigned to the sodium current in mutant channel model. A value of about $10000 \mathrm{~S} / \mathrm{F}$ allows the reproduction of coherent action potentials in WT and mutant cells.
\end{abstract}

\section{Introduction}

Congenital Brugada syndrome $(\mathrm{BrS})$ is an inherited disorder that causes severe ventricular arrhythmias and sudden death in young, otherwise healthy, subjects [1]. Typical electrocardiogram alterations in BrS are the STsegment elevation in the right precordial ECG lead and right bundle-branch block. Notably, the BrS phenotype is paroxystic [1], probably because of a BrS-induced augmented sensitivity to concurrent factors affecting the cardiac electrical activity.

Since 1998, when the gene encoding for the cardiac sodium channel (SCN5A) was shown to be responsible for some of the cases of $\mathrm{BrS}$, several different mutations have been identified [1]. However, the assessment of the functional consequences of BrS-associated SCN5A mutations is unavoidably biased by technical limitations of the current experimental methods. To overcome such technical limitations a novel approach based on the combination of in vitro data and computer modeling has been recently proposed [2]. We used this approach for the evaluation of the $\mathrm{Y} 1795 \mathrm{H}$ mutation affecting the $\mathrm{C}$ terminus of SCN5A protein. The sodium current $\left(\mathrm{I}_{\mathrm{Na}}\right)$ abnormalities due to $\mathrm{Y} 1795 \mathrm{H}$ have been previously studied in vitro by voltage clamp in heterologously expressed channels [3] and a markovian model capable to reproduce the $\mathrm{I}_{\mathrm{Na}}$ experimental characteristics of both wild type and $\mathrm{Y} 1795 \mathrm{H}$ has been developed [4]. The markovian $\mathrm{I}_{\mathrm{Na}}$ model is here incorporated into the LuoRudy comprehensive dynamical model (LRd) of cardiac ventricular cells [5]. It is worth noting that experimental current recordings allow assessing current kinetics, but the uncontrolled expression of the channel in the heterologous system does not permit to identify the maximum $\mathrm{I}_{\mathrm{Na}}$ conductance $\left(G_{\text {Namax }}\right)$ to be used for the simulation of the cardiac action potential (AP). The uncertainty in the assignment of the $G_{\text {Namax }}$ parameter affects the prediction of LRd model.

In the present study the impact of different values of $G_{\text {Namax }}$ on the simulated action potential is analyzed and discussed considering both the wild type and mutant $\mathrm{Na}$ channels.

\section{Methods}

The general approach to simulate the cardiac action potential by using the LRd model of a ventricular cell is extensively described in [5]. The latest version of the LRd model [6] was implemented in Simulink 5 (The MathWorks. Inc). The Markov formulation of $\mathrm{I}_{\mathrm{Na}}$ included in the LRd model, as well as the identification of the kinetic rates over experimental voltage clamp recordings in heterologously expressed channels (HEK293 cells), is presented in [3;4].

Simulations were performed considering isolated epicardial (epi), endocardial (endo), and midmyocardial (M) cells, which were simulated by assigning different values to the maximum conductance of the slowly activating delayed-rectifier potassium current, $G_{K s}$, and of the transient outward current, $G_{t o}$, as described in previous experimental and simulation studies [7-10]. In epicardial cells $G_{t o}$ was set to $1100 \mathrm{~S} / \mathrm{F}$ and the density ratio of $\mathrm{I}_{\mathrm{Ks}}$ to $\mathrm{I}_{\mathrm{Kr}}$ (the rapidly activating delayed rectifier potassium current), $G_{K s} / G_{K r}$, was set to 63 . In M cells, $G_{t o}=500 \mathrm{~S} / \mathrm{F}$ and $G_{K s} / G_{K r}=23.3$. In endocardial cells, $G_{t o}=50 \mathrm{~S} / \mathrm{F}$ and $G_{K s} / G_{K r}=29.6$. 


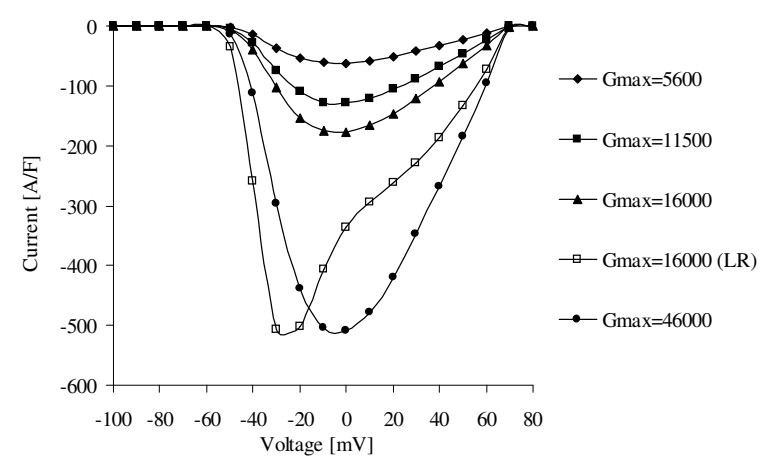

Figure 1. Current voltage relation of wild-type $\mathrm{I}_{\mathrm{Na}}$ for different maximum conductances $G_{\text {Namax }}$ (see text).

In all the cells, the maximum conductance of the L-Type calcium current was decreased by $30 \%$ with respect to the original LRd formulation, in accordance with [8].

All the simulations were repeated for different values of $G_{\text {Namax }}$ chosen within the wide range reported in previous experimental and simulation studies. Taking into consideration that $\mathrm{Y} 1795 \mathrm{H}$ carriers have one normal and one mutant allele, the Y1795H APs were simulated by setting $50 \%$ wild type and $50 \%$ Y $1795 \mathrm{H}$ channels. The ratio between WT and Y1795H $G_{\text {Namax }}$ was set to 2.7, in order to reproduce the ratio between experimental peak current densities recorded in HEK293 cells [3].

Figure 1 shows the current voltage relation of WT Na channels for the different $G_{\text {Namax }}$ values considered in the present analysis. $G_{\text {Namax }}=16000 \mathrm{~S} / \mathrm{F}$ is the value used in the Hodgkin-Huxley-like $\mathrm{I}_{\mathrm{Na}}$ formulation of the original LRd model [5]. $G_{\text {Namax }}=46000 \mathrm{~S} / \mathrm{F}$ gives the same maximal peak current of the original LRd with our markovian $\mathrm{I}_{\mathrm{Na}}$ formulation. $G_{\text {Namax }}=11500 \mathrm{~S} / \mathrm{F}$ allows a good fitting of the peak current expressed in HEK293 cells [3]. $G_{\text {Namax }}=5600 \mathrm{~S} / \mathrm{F}$ was calculated on experimental data [11] from guinea pig cells.

All the simulations (duration $5 \mathrm{~s}$ ) were performed on a MS-DOS Pentium computer, by using Rosenbrock variable step algorithm (max step $0.1 \mathrm{~ms}$ ). The cells were excited with a train of current pulses (duration: $0.001 \mathrm{~s}$, amplitude: 50 [A/F], frequency: $40 \mathrm{bpm}$ ).
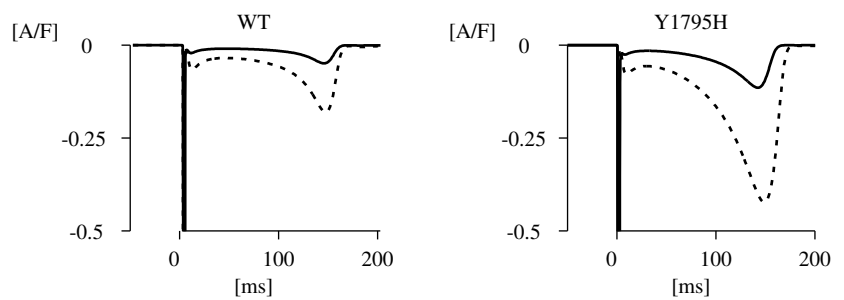

— Gmax $=11500 \mathrm{~S} / \mathrm{F}$

- . Gmax $=16000 \mathrm{~S} / \mathrm{F}$

Figure 2. Simulated macroscopic sustained WT and $\mathrm{Y} 1795 \mathrm{H}$ currents in an isolated endocardial cell for two different values of the maximum sodium current conductance, $G_{\text {Namax }}$.

\section{Results}

Examples of simulated $\mathrm{I}_{\mathrm{Na}}$ current during $\mathrm{AP}$ are shown in Figure 2. The model correctly reproduces the increased sustained sodium current in $\mathrm{Y} 1795 \mathrm{H}$ with respect to WT, which is a distinctive feature of this mutation. Moreover, the sustained current is increasing with the maximum $\mathrm{I}_{\mathrm{Na}}$ conductance, but the influence of $G_{\text {Namax }}$. on the sustained current is much greater in the case of $\mathrm{Y} 1795 \mathrm{H}$ mutation than in WT. As a direct consequence, the AP computed in $\mathrm{Y} 1795 \mathrm{H}$ is more critically sensitive to $G_{\text {Namax }}$ assignment than in the WT case (see Figure 3). In particular, the increase of $G_{\text {Namax }}$ causes a progressive enhancement of AP durations in Y1795H, especially in M cells, that was not evident in the WT. Even, in the $\mathrm{M}$ cell the maximal value of $G_{\text {Namax }}$ induces EADs in $\mathrm{Y} 1795 \mathrm{H}$ (Figure 3, right panel). On converse, a variation of $G_{\text {Namax }}$ conductance in wild type channels does not produce an increase of AP durations (Figure 3, left panel).

Notably, even if for a low $G_{\text {Namax }}$ the WT and mutant APs are similar in basal conditions, cells with mutant channels exhibite a larger susceptibility to the concurrent perturbation of other factors. As an example, an enhanced transient outward potassium current, simulated by a 3fold increase of $G_{t o}$ conductance, dramatically changes the AP in mutant epicardial cell: the spike and dome morphology with relatively long duration switches to a short triangular AP that lacks plateau phase (Figure 4, right panel).

\section{Discussion}

The present analysis shows that assignment of the $G_{\text {Namax }}$ parameter can be considered non critical in WT condition. In fact, the enhancement of $G_{\text {Namax }}$ induces an increment of $\mathrm{I}_{\mathrm{Na}}$ peak that has little effect on the AP morphology, affecting only the upstroke velocity. The enhancement of $G_{\text {Namax }}$ also induces an increase of the sustained current that is much greater in $\mathrm{Y} 1795 \mathrm{H}$ than in WT (see Figure 2). The augmented sustained current has no effect in the WT but it becomes evident in the $\mathrm{Y} 1795 \mathrm{H}$, where the possibility of EADs arises in $\mathrm{M}$ cell (Figure 3, right panel). Thus, the choice of $G_{\text {Namax }}$ becomes critical in mutated conditions, when a variation of the sustained current amplitude directly affects the AP. Since $G_{\text {Namax }}$ is not clearly identifiable on the basis of expression studies in heterologous systems, a sensitivity analysis to this parameter was considered important in order to draw consistent pathophysiological indications from simulation results.

In particular, a mutation-induced AP lengthening is not coherent with clinical observations on the $\mathrm{Y} 1795 \mathrm{H}$ family, which reported QT interval within normal values [3], while a QT prolongation would be expected following the prolongation of cellular action potential reported by simulation (Figure 3, left panel). On converse, a situation of no evident influence of mutation 
WT
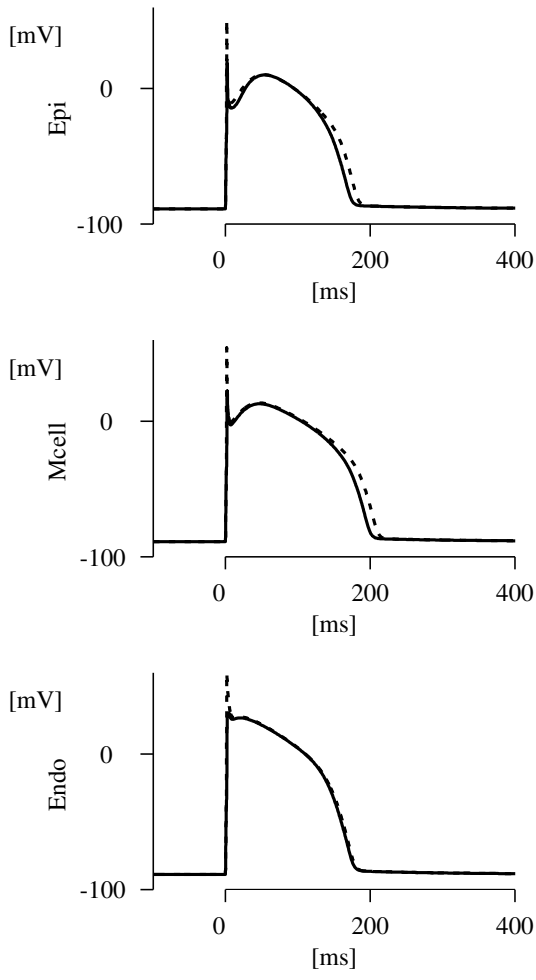

— Gmax=11500 S/F . . . G Gmax=46000 S/F
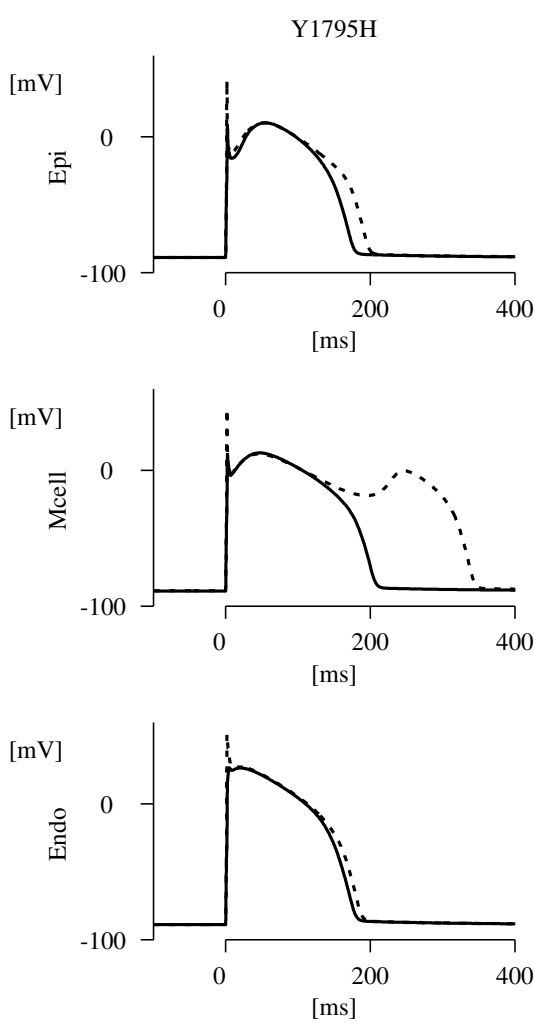

_ Gmax=11500 S/F _. . . Gmax=46000 S/F

Figure 3. Simulated effects of the maximum sodium current conductance, $G_{\text {Namax }}$, on action potentials of epicardial, midmyocardial and endocardial cells for wild type and $\mathrm{Y} 1795 \mathrm{H}$ mutation.

on AP characteristics in basal conditions could agree with the ECG phenotype of the gene carriers: in fact the typical pattern of ST segment elevation was present, at rest, only intermittently in one of them [3]. Taken together these observations suggest the lower values of $G_{\text {Namax }}$ as the best choice to reproduce realistic conditions.

The analysis with enhanced $G_{t o}$ points out that the functional alterations of $\mathrm{I}_{\mathrm{Na}}$ in $\mathrm{BrS}$, which can be well tolerated by the cell in normal conditions, could induce an augmented sensitivity to other factors. In fact, the heterogeneity of AP patterns shown in Figure 4 (right panel) is consistent with models proposed to explain ST segment elevation in $\mathrm{BrS}$ [1]. Once again the assignment of $G_{\text {Namax }}$ seems critical when $\mathrm{BrS}$ conditions are to be simulated and the better consistence with clinical observation is gained with a low $G_{\text {Namax }}$, High sodium conductance leads to higher inward current, capable to largely compensate the effect of the enhanced $\mathrm{I}_{\mathrm{to}}$.

\section{Conclusions}

The presented results highlight the high sensitivity of simulated AP of virtual transgenic cells to the maximum conductance assigned to the current in the mutant channel model. This aspect should be carefully considered when performing simulations of the whole cell behavior in presence of channel mutations.
The analysis performed on $\mathrm{Y} 1795 \mathrm{H}$ mutation leads to the conclusion that a value of $G_{\text {Namax }}$ of about $10000 \mathrm{~S} / \mathrm{F}$ allows the reproduction of several features of whole cell electrical activity that are consistent with the BrS phenotype.

Finally, we can confirm that the emerging approach to the study of cardiac congenital diseases, based on in silico simulations, allows filling the gap between the in vitro functional assessments and the clinical phenotype, providing novel pathophysiological insights potentially useful for patient management.

\section{Acknowledgements}

We thank E. Grandi for her help in performing simulations and preparing figures.

\section{References}

[1] Antzelevitch C, Brugada P, Brugada J, Brugada R, Towbin JA, Nademanee K. Brugada Syndrome:1992-2002 A Historical Perspective. J Am Coll Cardiol 41, 1665-1671. 2003.

[2] Clancy CE, Rudy Y. Linking a genetic defect to its cellular phenotype in a cardiac arrhythmia. Nature 1999; 400(6744):566-569.

[3] Rivolta I, Abriel H, Tateyama M, Liu H, Memmi M, Vardas $\mathrm{P}$ et al. Inherited Brugada and long QT-3 syndrome mutations of a single residue of the cardiac sodium channel 

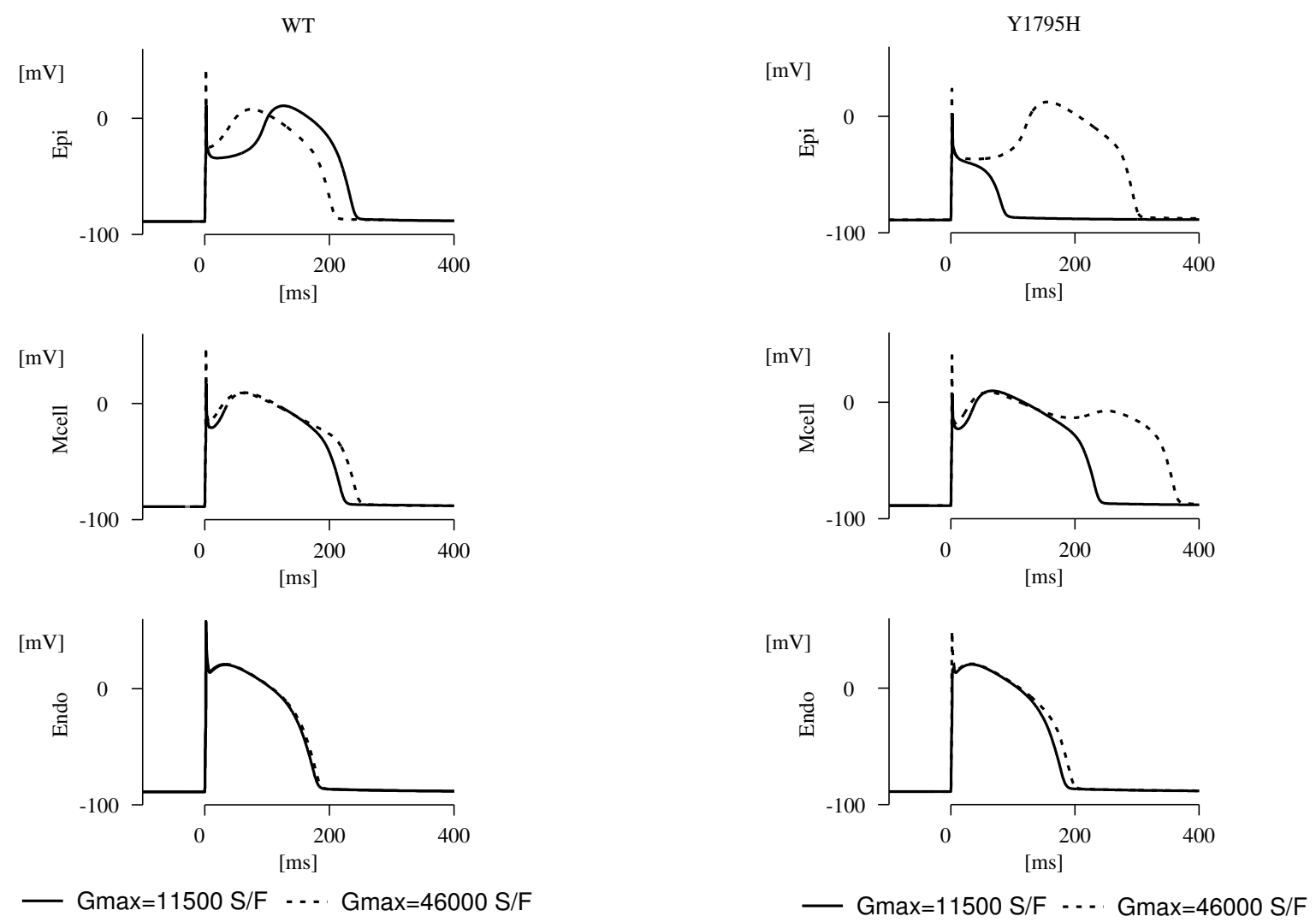

Figure 4. Simulated effects of the maximum sodium current conductance, $G_{\text {Namax }}$, on action potentials for wild type and Y1795H mutation in presence of enhanced transient outward potassium current.

confer distinct channel and clinical phenotypes. J Biol Chem 2001; 276(33):30623-30630.

[4] Vecchietti S, Rivolta I, Severi S, Napolitano C, Priori SG, Cavalcanti S. Markovian Model for Wild-Type and Mutant (Y1795C and Y1795H) Human Cardiac Na+ Channel. Computers in Cardiology 2003; $\tilde{\square}$.

[5] Luo CH, Rudy Y. A dynamic model of the cardiac ventricular action potential. I. Simulations of ionic currents and concentration changes. Circ Res 1994; 74(6):10711096.

[6] Faber GM, Rudy Y. Action potential and contractility changes in $[\mathrm{Na}(+)](\mathrm{i})$ overloaded cardiac myocytes: a simulation study. Biophys J 2000; 78(5):2392-2404.

[7] Viswanathan PC, Shaw RM, Rudy Y. Effects of IKr and IKs heterogeneity on action potential duration and its rate dependence: a simulation study. Circulation 1999; 99(18):2466-2474.

[8] Dumaine R, Towbin JA, Brugada P, Vatta M, Nesterenko DV, Nesterenko VV et al. Ionic mechanisms responsible for the electrocardiographic phenotype of the Brugada syndrome are temperature dependent. Circ Res 1999; 85(9):803-809.
[9] Greenstein JL, Wu R, Po S, Tomaselli GF, Winslow RL. Role of the calcium-independent transient outward current I(to1) in shaping action potential morphology and duration. Circ Res 2000; 87(11):1026-1033.

[10] Liu DW, Gintant GA, Antzelevitch C. Ionic bases for electrophysiological distinctions among epicardial, midmyocardial, and endocardial myocytes from the free wall of the canine left ventricle. Circ Res 1993; 72(3):671687.

[11] Tsushima RG, Kelly JE, Salata JJ, Liberty KN, Wasserstrom JA. Modification of cardiac $\mathrm{Na}(+)$ current by RWJ 24517 and its enantiomers in guinea pig ventricular myocytes. J Pharmacol Exp Ther 1999; 291(2):845-855.

Address for correspondence.

Severi Stefano.

Biomedical Engineering Laboratory,

DEIS, University of Bologna,

Via Venezia, 52

40123 Cesena (FC), Italy.

sseveri@deis.unibo.it 